\title{
Extended Piano Techniques and Teaching in Music Education Departments
}

\author{
Şirin Akbulut Demirci, Mete Sungurtekin, Nilüfer Yilmaz, Doruk Engür \\ Uludag University, Bursa, Turkey
}

\begin{abstract}
The article is composed of the results of the study carried out within the scope of the project entitled "Extended Piano Techniques and Teaching in Music Education Departments". Within the scope of the project, 16 students taking education at Music Education Department, Uludag University, learned six pieces composed for the project via benefiting from extended techniques and methodically during three semesters and their progress was evaluated via using the statistical data on the observation forms prepared beforehand. Moreover, in the end of the practice, with semi-structured questions, six students were interviewed and the contribution of the project to the students was investigated. The aim of the project is to investigate into the attitudes of the students towards teaching modern piano techniques at Education Faculty, Fine Arts Education Department, Music Education Division and their contribution to their success levels. As a result of the statistical data, when measurements made in the first and last weeks via using observation forms are taken into consideration, it can be stated that the first work developed target behaviors greatly during the five-week education process. It was observed that while the second, third, and fourth works had moderate level of effects on the development of target behaviors, the fifth and the sixth works had lower effects when compared to other works. According to the answers which six students gave to the semi-structured interview questions, all the students found the project positive in terms of its having them acquire a different perspective and five students found it positive in terms of its developing their information. A student stated that the allotted time was not sufficient, and another one found it unnecessarily detailed and stated a negative opinion. The originality of the study comes from the fact that these techniques in piano were new for the students at education faculties and applied for the first time.
\end{abstract}

Keywords: extended piano techniques, piano education, piano pedagogy, music education, Turkey

\section{Introduction}

The UAP(E)-2010/61 numbered project entitled "Extended Piano Techniques and Teaching in Music Education Departments" was accepted by Uludag University, Scientific Studies Unit, as a small-scale applied research project in 2010. The aim of the project entitled "Extended Piano Techniques and Teaching in Music Education Departments" was to investigate into the attitudes of the students towards teaching extended piano techniques at Education Faculty, Fine Arts Education Department, Music Education Division and their contribution to their success levels. The project lasted three years (2010-2013). For the project, first of all, in

Şirin Akbulut Demirci, D.M.A., associate professor, Music Education Department, Faculty of Education, Uludag University. Mete Sungurtekin, Ph.D., assistant professor, Music Education Department, Faculty of Education, Uludag University.

Nilüfer Yilmaz, lecturer, Music Education Department, Faculty of Education, Uludag University.

Doruk Engür, research assistant, Music Education Department, Faculty of Education, Uludag University. 
the first five months, composer Mesruh Savaş (1978- ) was asked to write six methodical compositions performed with modern piano techniques for the students receiving education at Education Faculty, Fine Arts Education Department, Music Education Division (five for solo piano and one for two players). The compositions were taught by the Music Education Division piano teaching staff members to 16 (two by each staff member) second-year students who volunteered to learn these techniques and were appropriate for this practice starting from 2011 Fall Semester and lasting three semesters, and hence, it was planned to observe the behaviors, attitudes, and learning levels of 16 students during three semesters. For this purpose, for each student, a personal observation form was prepared and evaluated. Following the project application stage, six students were interviewed via using semi-structured questions. The project application stage was completed via organizing a project ending concert (İsmail \& Şirin, 2013). In the project ending concert, seven of the students participated in the project performed the compositions and the other six of the participating students were assigned in the prepared presentation to introduce the extended techniques. The presentation text of the concert, extended piano techniques, was composed of quotations from the introduction section of the study entitled "The Use of Extended Piano Techniques at Conservatories in Turkey" and presented by research assistant Şirin Akbulut at the World Conference on Educational Sciences (WCES) Conference held between 4-8 February, 2010 (Şirin, $2010^{1}$ ). In the study, the techniques were explained by grouping, information about the composers using these techniques was given and supported by example videos.

While foreign resources explaining extended piano techniques are available, there is not a Turkish resource introducing these techniques fully and explaining how they work. The only Turkish resource is the proficiency-in-art dissertation prepared by Serla Balkarlı Can at Anadolu University, Social Sciences Institute in November 2002, entitled “John Cage's 'Prepared Piano' and Indonesian Traditional Orchestra Gamelan" (Can, 2002). In this dissertation, Can (2002) provided structured information about John Cage's prepared piano and his life, books, works, and musical styles, and New York School. Moreover, it includes notes which Fuat Kent wrote in German and used when introducing modern piano techniques in his seminars. In the study entitled "The Use of Extended Piano Techniques at Conservatories in Turkey" (Şirin, 2010), the role of extended techniques piano repertoire in the pedagogical approaches of instructors at conservatoires was analyzed. Results indicated that these techniques were not widely taught and the repertoire was not widely performed. And also, in the article entitled "Extended Piano Techniques and Two Pieces of Music", which was written by Şirin and Mesruh (2012) and published in the International Journal of New Trends in Art, Sports and Science Education in 2012, some techniques were introduced. In this study, Mesruh Savaş's (1978- ) first two compositions which were composed for the project "Extended Piano Techniques and Teaching in Music Education Departments" were chosen as an example and were analyzed. Their contribution to music literature and their place and importance were examined and searched. Thus, it was observed that the extended techniques utilized in these pieces are playing pizzicato with right and left hands fingertips, using different tools like chisel and paper clips for achieving different colors (Şirin \& Mesruh, 2012). At the third and fourth pieces, these extended techniques were detected: (a) prepared piano; (b) string piano; (c) whistling, singing, or talking into the piano; (d) silently depressing one or more keys, allowing the corresponding strings to vibrate freely; thus, creating a kind of reverb effect; (e) percussive use of different parts of the piano, such as the outer

\footnotetext{
${ }^{1}$ For more detailed information, you can examine the article at the Website http://www.sciencedirect.com/science/article/ pii/S1877042810005094.
} 
rim; and (f) microtones (Şirin, 2012). Last two compositions were observed that the extended techniques utilized in these pieces are playing pizzicato with right and left hands fingertips, glissando, using different tools like paper clips for achieving different colors and using different pedal techniques (Şirin, 2013).

At the "New Trends on Global Education Conference" held in the Turkish Republic of Northern Cyprus in 2012, Nilüfer Y1lmaz presented a paper on this subject. In this study, in relation to the teaching of extended piano techniques in music education, based on two-semester application of the project entitled "Extended Piano Techniques and Teaching in Music Education Departments" at Uludag University, Education Faculty, Fine Arts Education Department, Music Education Division, teaching staff members and students' attitudes towards and opinions about modern piano techniques aimed to be determined. In conclusion, it was determined that the teaching staff members and the students found it important and necessary to teach these techniques, had some reservations about practicing them, but held the opinion that performing pieces of music written via using modern piano techniques would change piano education, creativity, and view of contemporary music in a positive way (Nilüfer, 2012). This finding verifies the findings obtained in our study.

\section{Methods}

The data obtained via the observation forms prepared to investigate into behaviors, attitudes, and learning levels over the course of three years were analyzed through using the Statistical Package for Social Sciences (SPSS) Statistics Version 22.0 program. In the end of the project application stage, six students were interviewed by using semi-structured questions.

In this section of the study, the semi-structured interview form prepared by the researchers was used to collect data. The questions were determined beforehand and data tried to be collected via these questions. Fundamental issues were themed and the semi-structured interview form was prepared. In the end of this process, a pilot interview was held. Through the prepared interview form, interviews were held with the participants. The data obtained from the study were divided into meaningful sections by the researchers and these sections were coded. These created codes were used in the examination and arrangement of the data.

\section{Findings}

\section{Findings Obtained From the Personal Observation Forms}

In the analyses made to test if there were any significant differences between the attainment levels of target behaviors according to weeks, since the sphericity requirement was not fulfilled, the Friedman test, a non-parametric test, was used. In cases where the Friedman test was found significant, the Wilcoxon test was employed to determine in which week(s) there were developments in the target behavior.

The first composition. Since two of the 16 participating students did not participate in the practice in the fourth week, the test was evaluated over 14 students.

According to the result of the Friedman test, the students' levels of attaining the behavior "Being able to mark the notes with stickers on the piano wire" (Beh. 1) of the first composition showed significant development according to weeks $\left(\chi_{(4)}^{2}=29.239 ; p<0.01\right)$. Wilcoxon tests showed that significant changes are between weeks 1-3, 1-4, 1-5, 2-3, 2-4, 2-5, 3-4, and 3-5 ( $p<0.05)$ (see Table 1).

According to the result of the Friedman test, the students' levels of attaining the behavior "Being able to read the modern notation" (Beh. 2) of the first composition showed significant development according to weeks, 
$\left(\chi_{(4)}^{2}=50.574 ; p<0.01\right)$. Wilcoxon tests showed that significant changes are between weeks $1-2,1-3,1-4,1-5$, $2-3,2-4,2-5,3-4,3-5$, and 4-5 $(p<0.05)$.

Table 1

Distribution of Target Behavior Scores in the First Composition According to Weeks

\begin{tabular}{|c|c|c|c|c|c|c|c|c|c|c|c|}
\hline \multirow{2}{*}{ Behavior } & \multicolumn{2}{|c|}{ Week 1} & \multicolumn{2}{|c|}{ Week 2} & \multicolumn{2}{|c|}{ Week 3} & \multicolumn{2}{|c|}{ Week 4} & \multicolumn{2}{|c|}{ Week 5} & \multirow{2}{*}{$\begin{array}{l}\chi_{(4)}^{2} \\
(N=14)\end{array}$} \\
\hline & $\bar{M}$ & $S D$ & $\bar{M}$ & $S D$ & $M$ & $S D$ & $\bar{M}$ & $S D$ & $\bar{M}$ & $S D$ & \\
\hline Beh. 1 & 3.57 & 1.453 & 4.00 & 1.177 & 4.36 & 0.929 & 4.64 & 0.745 & 4.79 & 0.426 & $29.239^{* *}$ \\
\hline Beh. 2 & 2.00 & 0.961 & 2.50 & 0.855 & 3.57 & 0.756 & 3.93 & 0.475 & 4.50 & 0.650 & $50.574^{* *}$ \\
\hline Beh. 3 & 3.00 & 1.177 & 3.43 & 0.938 & 4.07 & 0.616 & 4.43 & 0.646 & 4.79 & 0.426 & $37.014^{* *}$ \\
\hline Beh. 4 & 2.86 & 1.231 & 3.07 & 1.269 & 3.71 & 1.069 & 4.21 & 0.893 & 4.50 & 0.650 & $36.203^{* *}$ \\
\hline Beh. 5 & 3.00 & 1.240 & 3.50 & 0.941 & 4.00 & 0.555 & 4.64 & 0.497 & 4.86 & 0.363 & $41.592^{* *}$ \\
\hline Beh. 6 & 2.29 & 0.825 & 2.57 & 1.089 & 3.21 & 1.051 & 3.71 & 0.994 & 4.14 & 0.864 & $41.524^{* *}$ \\
\hline Beh. 7 & 3.14 & 1.099 & 3.71 & 0.825 & 4.14 & 0.663 & 4.43 & 0.514 & 4.79 & 0.426 & $32.729^{* *}$ \\
\hline Beh. 8 & 2.43 & 0.852 & 3.00 & 1.109 & 3.36 & 1.082 & 3.93 & 0.616 & 4.50 & 0.760 & $41.519^{* *}$ \\
\hline Beh. 9 & 1.71 & 0.825 & 2.21 & 0.975 & 2.79 & 0.893 & 3.50 & 0.855 & 3.93 & 0.616 & $48.614^{* *}$ \\
\hline Beh. 10 & 2.50 & 0.941 & 2.86 & 0.949 & 3.50 & 0.941 & 3.93 & 0.616 & 4.29 & 0.825 & $46.991^{* *}$ \\
\hline Beh. 11 & 1.93 & 0.917 & 2.57 & 0.938 & 3.50 & 0.760 & 3.71 & 0.825 & 4.29 & 0.914 & $44.589^{* *}$ \\
\hline Beh. 12 & 1.79 & 0.802 & 2.36 & 1.008 & 3.00 & 1.038 & 3.57 & 0.852 & 4.07 & 0.917 & $45.903^{* *}$ \\
\hline Beh. 13 & 2.29 & 1.139 & 2.86 & 1.099 & 3.29 & 0.825 & 3.86 & 0.864 & 4.07 & 0.829 & $44.239^{* *}$ \\
\hline Beh. 14 & 2.50 & 0.941 & 2.86 & 0.864 & 3.57 & 1.016 & 3.93 & 0.829 & 4.36 & 0.842 & $38.178^{* *}$ \\
\hline Beh. 15 & 2.21 & 1.251 & 2.71 & 1.204 & 3.21 & 1.122 & 3.79 & 0.893 & 4.00 & 0.784 & $36.252^{* *}$ \\
\hline Total mean score & 2.48 & 0.726 & 2.95 & 0.728 & 3.55 & 0.602 & 4.01 & 0.453 & 4.39 & 0.476 & $55.655^{* *}$ \\
\hline
\end{tabular}

Note. ${ }^{*} p<0.05$ and ${ }^{* *} p<0.01$ behaviors were scored between $1-5$ points.

According to the result of the Friedman test, the students' levels of attaining the behavior "Being able to play pizzicato on the piano wire with right hand fingertips" (Beh. 3) of the first composition showed significant development according to weeks $\left(\chi_{(4)}^{2}=37.014 ; p<0.01\right)$. Wilcoxon tests showed that significant changes are between weeks 1-2, 1-3, 1-4, 1-5, 2-3, 2-4, 2-5, 3-4, 3-5, and 4-5 ( $p<0.05)$.

According to the result of the Friedman test, the students' levels of attaining the behavior "Being able to silence the keys immediately by using the pedal" (Beh. 4) of the first composition showed significant development according to weeks $\left(\chi_{(4)}^{2}=36.203 ; p<0.01\right)$. Wilcoxon tests showed that significant changes are between weeks 1-3, 1-4, 1-5, 2-3, 2-4, 2-5, 3-4, 3-5, and 4-5 $(p<0.05)$.

According to the result of the Friedman test, the students' levels of attaining the behavior "Being able to play glissando on the wire with metal bar" (Beh. 5) of the first composition showed significant development according to weeks $\left(\chi_{(4)}^{2}=41.592 ; p<0.01\right)$. Wilcoxon tests showed that significant changes are between weeks 1-2, 1-3, 1-4, 1-5, 2-3, 2-4, 2-5, 3-4, and 3-5 $(p<0.05)$.

According to the result of the Friedman test, the students' levels of attaining the behavior "Being able to play on the keys with left hand while playing glissando with right hand on the wire with metal bar" (Beh. 6) of the first composition showed significant development according to weeks $\left(\chi_{(4)}^{2}=41.524 ; p<0.01\right)$. Wilcoxon tests showed that significant changes are between weeks 1-3, 1-4, 1-5, 2-3, 2-4, 2-5, 3-4, 3-5, and 4-5 ( $p<0.05)$.

According to the result of the Friedman test, the students' levels of attaining the behavior "Being able to play pizzicato on the piano wire with left hand fingertips" (Beh. 7) of the first composition showed significant development according to weeks $\left(\chi_{(4)}^{2}=32.729 ; p<0.01\right)$. Wilcoxon tests showed that significant changes are between weeks 1-2, 1-3, 1-4, 1-5, 2-4, 2-5, 3-4, 3-5, and 4-5 $(p<0.05)$. 
According to the result of the Friedman test, the students' levels of attaining the behavior "Being able to play on the keys with right hand while playing pizzicato one the piano wire with left hand fingertips" (Beh. 8) of the first composition showed significant development according to weeks $\left(\chi_{(4)}^{2}=41.519 ; p<0.01\right)$. Wilcoxon tests showed that significant changes are between weeks 1-2, 1-3, 1-4, 1-5, 2-4, 2-5, 3-4, 3-5, and 4-5 $(p<0.05)$.

According to the result of the Friedman test, the students' levels of attaining the behavior "Being able to act rapidly while playing on the keys and playing extended piano techniques on the wire" (Beh. 9) of the first composition showed significant development according to weeks $\left(\chi_{(4)}^{2}=48.614 ; p<0.01\right)$. Wilcoxon tests showed that significant changes are between weeks 1-2, 1-3, 1-4, 1-5, 2-3, 2-4, 2-5, 3-4, 3-5, and 4-5 ( $p<0.05)$.

According to the result of the Friedman test, the students' levels of attaining the behavior "Being able to create the metallic sounds required by the composer" (Beh. 10) of the first composition showed significant development according to weeks $\left(\chi_{(4)}^{2}=46.991 ; p<0.01\right)$. Wilcoxon tests showed that significant changes are between weeks 1-2, 1-3, 1-4, 1-5, 2-3, 2-4, 2-5, 3-4, 3-5, and 4-5 $(p<0.05)$.

According to the result of the Friedman test, the students' levels of attaining the behavior "Being able to play appropriate and different dynamics of the piece" (Beh. 11) of the first composition showed significant development according to weeks $\left(\chi_{(4)}^{2}=44.589 ; p<0.01\right)$. Wilcoxon tests showed that significant changes are between weeks 1-2, 1-3, 1-4, 1-5, 2-3, 2-4, 2-5, 3-5, and 4-5 ( $p<0.05)$.

According to the result of the Friedman test, the students' levels of attaining the behavior "Being able to play appropriate and different tempos of the piece" (Beh. 12) of the first composition showed significant development according to weeks $\left(\chi_{(4)}^{2}=45.903 ; p<0.01\right)$. Wilcoxon tests showed that significant changes are between weeks 1-2, 1-3, 1-4, 1-5, 2-3, 2-4, 2-5, 3-4, 3-5, and 4-5 $(p<0.05)$.

According to the result of the Friedman test, the students' levels of attaining the behavior "Being able to play on the keys with right hand while playing pizzicato on the piano wire with left hand fingernails" (Beh. 13) of the first composition showed significant development according to weeks $\left(\chi_{(4)}^{2}=44.239 ; p<0.01\right)$. Wilcoxon tests showed that significant changes are between weeks 1-2, 1-3, 1-4, 1-5, 2-3, 2-4, 2-5, 3-4, and 3-5 $(p<0.05)$.

According to the result of the Friedman test, the students' levels of attaining the behavior "Being able to play different dynamics on the piano wire with right hand" (Beh. 14) of the first composition showed significant development according to weeks $\left(\chi_{(4)}^{2}=38.178 ; p<0.01\right)$. Wilcoxon tests showed that significant changes are between weeks 1-3, 1-4, 1-5, 2-3, 2-4, 2-5, 3-5, and 4-5 $(p<0.05)$.

According to the result of the Friedman test, the students' levels of attaining the behavior "Being able to read three part notation" (Beh. 15) of the first composition showed significant development according to weeks $\left(\chi_{(4)}^{2}=36.252 ; p<0.01\right)$. Wilcoxon tests showed that significant changes are between weeks 1-3, 1-4, 1-5, 2-3, $2-4,2-5,3-4$, and 3-5 $(p<0.05)$.

In consideration of the total mean score, the students' levels of attaining the behaviors of the first composition showed significant development according to weeks $\left(\chi_{(4)}^{2}=55.655 ; p<0.01\right)$. Wilcoxon tests showed that significant changes are between weeks 1-2, 1-3, 1-4, 1-5, 2-3, 2-4, 2-5, 3-4, 3-5, and 4-5 ( $p<0.05)$.

The second composition. Since one of the 16 participating students did not attend the practice in the second week and another one did not attend the practices both in the second and the fourth week, the test was evaluated over 14 students. 
According to the result of the Friedman test, the students' levels of attaining the behavior "Being able to mark the notes with stickers on the piano wire" (Beh. 1) of the second composition showed significant development according to weeks $\left(\chi_{(4)}^{2}=18.636 ; p<0.01\right)$. Wilcoxon tests showed that significant changes are between weeks 1-3, 1-4, 1-5, 2-3, 2-4, and 2-5 $(p<0.05)$ (see Table 2).

Table 2

Distribution of Target Behavior Scores in the Second Composition According to Weeks

\begin{tabular}{|c|c|c|c|c|c|c|c|c|c|c|c|}
\hline \multirow{2}{*}{ Behavior } & \multicolumn{2}{|c|}{ Week 1} & \multicolumn{2}{|c|}{ Week 2} & \multicolumn{2}{|c|}{ Week 3} & \multicolumn{2}{|c|}{ Week 4} & \multicolumn{2}{|c|}{ Week 5} & \multirow{2}{*}{$\begin{array}{l}\chi_{(4)}^{2} \\
(N=14)\end{array}$} \\
\hline & $M$ & $S D$ & $M$ & $S D$ & $\bar{M}$ & $S D$ & $\bar{M}$ & $S D$ & $M$ & $S D$ & \\
\hline Beh. 1 & 4.07 & 1.269 & 4.21 & 1.122 & 4.57 & 0.756 & 4.79 & 0.426 & 4.93 & 0.267 & $18.636^{* *}$ \\
\hline Beh. 2 & 2.79 & 1.188 & 3.36 & 1.082 & 3.64 & 0.929 & 4.21 & 0.699 & 4.57 & 0.514 & $41.010^{* *}$ \\
\hline Beh. 3 & 3.07 & 1.207 & 3.64 & 1.277 & 4.07 & 1.207 & 4.29 & 0.994 & 4.50 & 0.760 & $34.209^{* *}$ \\
\hline Beh. 4 & 3.43 & 0.514 & 4.00 & 0.555 & 4.50 & 0.519 & 4.79 & 0.426 & 4.86 & 0.363 & $40.489^{* *}$ \\
\hline Beh. 5 & 2.79 & 0.975 & 3.43 & 1.016 & 3.64 & 1.082 & 4.07 & 0.997 & 4.43 & 0.756 & $38.389^{* *}$ \\
\hline Beh. 6 & 3.57 & 0.852 & 4.14 & 0.663 & 4.57 & 0.646 & 4.64 & 0.497 & 4.79 & 0.426 & $32.690^{* *}$ \\
\hline Beh. 7 & 2.07 & 0.997 & 2.57 & 1.158 & 3.00 & 1.177 & 3.36 & 1.336 & 3.64 & 1.499 & $37.124^{* *}$ \\
\hline Beh. 8 & 3.50 & 0.760 & 3.79 & 0.893 & 4.26 & 0.497 & 4.64 & 0.497 & 4.86 & 0.363 & $36.656^{* *}$ \\
\hline Beh. 9 & 3.21 & 1.311 & 3.57 & 1.158 & 4.14 & 0.864 & 4.21 & 0.893 & 4.57 & 0.938 & $34.819^{* *}$ \\
\hline Beh. 10 & 2.07 & 0.997 & 2.64 & 0.745 & 2.79 & 0.699 & 3.57 & 0.852 & 4.00 & 1.038 & $44.338^{* *}$ \\
\hline Beh. 11 & 2.79 & 0.699 & 3.14 & 0.864 & 3.64 & 0.745 & 3.79 & 0.699 & 4.14 & 0.535 & $40.447^{* *}$ \\
\hline Beh. 12 & 2.79 & 0.893 & 3.36 & 1.216 & 3.79 & 0.802 & 3.86 & 0.864 & 4.36 & 0.745 & $35.451^{* *}$ \\
\hline Beh. 13 & 2.36 & 0.929 & 2.71 & 1.069 & 3.57 & 0.852 & 4.14 & 0.864 & 4.36 & 0.745 & $45.266^{* *}$ \\
\hline Beh. 14 & 2.57 & 1.089 & 2.86 & 1.167 & 3.71 & 0.825 & 3.86 & 1.099 & 4.14 & 0.864 & $37.941^{* *}$ \\
\hline Total mean score & 2.93 & 0.574 & 3.39 & 0.588 & 3.86 & 0.422 & 4.16 & 0.421 & 4.44 & 0.394 & $52.722^{* *}$ \\
\hline
\end{tabular}

Note. ${ }^{*} p<0.05$ and ${ }^{* *} p<0.01$ behaviors were scored between $1-5$ points.

According to the result of the Friedman test, the students' levels of attaining the behavior "Being able to read modern notation" (Beh. 2) of the second composition showed significant development according to weeks $\left(\chi_{(4)}^{2}=41.010 ; p<0.01\right)$. Wilcoxon tests showed that significant changes are between weeks 1-2, 1-3, 1-4, 1-5, 2-3, 2-4, 2-5, 3-4, 3-5, and 4-5 ( $p<0.05)$.

According to the result of the Friedman test, the students' levels of attaining the behavior "Being able to depress the keys by using sostenuto pedal" (Beh. 3) of the second composition showed significant development according to weeks $\left(\chi_{(4)}^{2}=34.209 ; p<0.01\right)$. Wilcoxon tests showed that significant changes are between weeks 1-2, 1-3, 1-4, 1-5, 2-3, 2-4, 2-5, and 3-5 $(p<0.05)$.

According to the result of the Friedman test, the students' levels of attaining the behavior "Being able to play glissando with iron coin on the piano wire" (Beh. 4) of the second composition showed significant development according to weeks $\left(\chi_{(4)}^{2}=40.489 ; p<0.01\right)$. Wilcoxon tests showed that significant changes are between weeks 1-2, 1-3, 1-4, 1-5, 2-3, 2-4, and 2-5 ( $p<0.05)$.

According to the result of the Friedman test, the students' levels of attaining the behavior "Being able to mute the sounds with left hand" (Beh. 5) of the second composition showed significant development according to weeks $\left(\chi_{(4)}^{2}=38.389 ; p<0.01\right)$. Wilcoxon tests showed that significant changes are between weeks 1-2, 1-3, $1-4,1-5,2-4,2-5,3-4,3-5$, and $4-5(p<0.05)$.

According to the result of the Friedman test, the students' levels of attaining the behavior "Being able to play pizzicato with iron triangle paper clip on the piano wire" (Beh. 6) of the second composition showed 
significant development according to weeks $\left(\chi_{(4)}^{2}=32.690 ; p<0.01\right)$. Wilcoxon tests showed that significant changes are between weeks 1-2, 1-3, 1-4, 1-5, 2-3, 2-4, and 2-5 $(p<0.05)$.

According to the result of the Friedman test, the students' levels of attaining the behavior "Being able to play the fifth interval of the $3 \mathrm{G}$ note's wire with the fingertip" (Beh. 7) of the second composition showed significant development according to weeks $\left(\chi_{(4)}^{2}=37.124 ; p<0.01\right)$. Wilcoxon tests showed that significant changes are between weeks 1-2, 1-3, 1-4, 1-5, 2-3, 2-4, 2-5, 3-4, 3-5, and 4-5 $(p<0.05)$.

According to the result of the Friedman test, the students' levels of attaining the behavior "Being able to play glissando with paper clip on the wire" (Beh. 8) of the second composition showed significant development according to weeks $\left(\chi_{(4)}^{2}=36.656 ; p<0.01\right)$. Wilcoxon tests showed that significant changes are between weeks 1-3, 1-4, 1-5, 2-3, 2-4, 2-5, 3-4, and 3-5 ( $p<0.05)$.

According to the result of the Friedman test, the students' levels of attaining the behavior "Being able to play pizzicato with left hand on the wires" (Beh. 9) of the second composition showed significant development according to weeks $\left(\chi_{(4)}^{2}=34.819 ; p<0.01\right)$. Wilcoxon tests showed that significant changes are between weeks 1-2, 1-3, 1-4, 1-5, 2-3, 2-4, 2-5, 3-5, and 4-5 $(p<0.05)$.

According to the result of the Friedman test, the students' levels of attaining the behavior "Being able to act rapidly while playing on the keys and playing extended piano techniques on the wire" (Beh. 10) of the second composition showed significant development according to weeks $\left(\chi_{(4)}^{2}=44.338 ; p<0.01\right)$. Wilcoxon tests showed that significant changes are between weeks 1-2, 1-3, 1-4, 1-5, 2-4, 2-5, 3-4, 3-5, and 4-5 $(p<0.05)$.

According to the result of the Friedman test, the students' levels of attaining the behavior "Being able to create the metallic sounds required by the composer" (Beh. 11) of the second composition showed significant development according to weeks $\left(\chi_{(4)}^{2}=40.447 ; p<0.01\right)$. Wilcoxon tests showed that significant changes are between weeks 1-2, 1-3, 1-4, 1-5, 2-3, 2-4, 2-5, 3-5, and 4-5 ( $p<0.05)$.

According to the result of the Friedman test, the students' levels of attaining the behavior "Being able to appropriate and different dynamics of the piece" (Beh. 12) of the second composition showed significant development according to weeks $\left(\chi_{(4)}^{2}=35.451 ; p<0.01\right)$. Wilcoxon tests showed that significant changes are between weeks 1-2, 1-3, 1-4, 1-5, 2-5, 3-5, and 4-5 ( $p<0.05)$.

According to the result of the Friedman test, the students' levels of attaining the behavior "Being able to appropriate and different tempos of the piece" (Beh. 13) of the second composition showed significant development according to weeks $\left(\chi_{(4)}^{2}=45.266 ; p<0.01\right)$. Wilcoxon tests showed that significant changes are between weeks 1-3, 1-4, 1-5, 2-3, 2-4, 2-5, 3-4, 3-5, and 4-5 ( $p<0.05)$.

According to the result of the Friedman test, the students' levels of attaining the behavior "Being able to play the keys with the right hand while playing pizzicato with paper clip on the piano wire" (Beh. 14) of the second composition showed significant development according to weeks $\left(\chi_{(4)}^{2}=37.941 ; p<0.01\right)$. Wilcoxon tests showed that significant changes are between weeks 1-3, 1-4, 1-5, 2-3, 2-4, 2-5, and 3-5 $(p<0.05)$.

In consideration of the total mean score, the students' levels of attaining the behaviors of the second composition showed significant development according to weeks $\left(\chi_{(4)}^{2}=52.722 ; p<0.01\right)$. Wilcoxon tests showed that significant changes are between weeks 1-2, 1-3, 1-4, 1-5, 2-3, 2-4, 2-5, 3-4, 3-5, and 4-5 ( $p<0.05)$.

The third composition. Because the level of the composition was high, five of 16 participating students did not attend the practice and another two did not attend the practices both in the first and the fourth week, the test was evaluated over nine students. 
According to the result of the Friedman test, the students' levels of attaining the behavior "Being able to mark the notes with stickers on the piano wire" (Beh. 1) of the third composition did not show significant development according to weeks $\left(\chi_{(4)}^{2}=8.583 ; p>0.05\right)$ (see Table 3 ).

Table 3

Distribution of Target Behavior Scores in the Third Composition According to Weeks

\begin{tabular}{|c|c|c|c|c|c|c|c|c|c|c|c|}
\hline \multirow{2}{*}{ Behavior } & \multicolumn{2}{|c|}{ Week 1} & \multicolumn{2}{|c|}{ Week 2} & \multicolumn{2}{|c|}{ Week 3} & \multicolumn{2}{|c|}{ Week 4} & \multicolumn{2}{|c|}{ Week 5} & \multirow{2}{*}{$\begin{array}{l}\chi_{(4)}^{2} \\
(N=9)\end{array}$} \\
\hline & $M$ & $S D$ & $M$ & $S D$ & $M$ & $S D$ & $M$ & $S D$ & $M$ & $S D$ & \\
\hline Beh. 1 & 4.44 & 0.726 & 4.56 & 0.527 & 4.78 & 0.441 & 4.78 & 0.441 & 4.89 & 0.441 & 8.583 \\
\hline Beh. 2 & 2.44 & 1.590 & 2.89 & 1.616 & 3.44 & 1.236 & 3.78 & 1.202 & 3.89 & 1.054 & $25.076^{* *}$ \\
\hline Beh. 3 & 2.44 & 1.333 & 3.00 & 1.658 & 3.22 & 1.202 & 3.44 & 1.333 & 3.89 & 1.054 & $23.848^{* *}$ \\
\hline Beh. 4 & 2.78 & 1.202 & 3.56 & 1.014 & 3.78 & 0.972 & 3.89 & 1.054 & 4.11 & 0.782 & $22.574^{* *}$ \\
\hline Beh. 5 & 2.56 & 0.882 & 2.89 & 0.782 & 3.11 & 0.601 & 3.78 & 0.667 & 4.33 & 0.866 & $26.210^{* *}$ \\
\hline Beh. 6 & 2.00 & 1.323 & 2.22 & 0.972 & 2.78 & 0.972 & 3.33 & 0.866 & 3.56 & 1.014 & $24.160^{* *}$ \\
\hline Beh. 7 & 2.44 & 1.130 & 2.78 & 1.202 & 3.44 & 1.130 & 3.56 & 1.130 & 3.78 & 0.972 & $22.353^{* *}$ \\
\hline Beh. 8 & 2.22 & 0.833 & 2.56 & 0.726 & 3.11 & 0.601 & 3.56 & 0.726 & 4.00 & 0.866 & $25.000^{* *}$ \\
\hline Total mean score & 2.67 & 0.893 & 3.05 & 0.808 & 3.46 & 0.682 & 3.76 & 0.789 & 4.06 & 0.768 & $33.120^{* *}$ \\
\hline
\end{tabular}

Note. ${ }^{*} p<0.05$ and ${ }^{* *} p<0.01$ behaviors were scored between $1-5$ points.

According to the result of the Friedman test, the students' levels of attaining the behavior "Being able to read modern notation" (Beh. 2) of the third composition showed significant development according to weeks $\left.\chi_{(4)}^{2}=25.076 ; p<0.01\right)$. Wilcoxon tests showed that significant changes are between weeks 1-2, 1-3, 1-4, 1-5, $2-3,2-4,2-5$, and 3-5 $(p<0.05)$.

According to the result of the Friedman test, the students' levels of attaining the behavior "Being able to play on prepared piano" (Beh. 3) of the third composition showed significant development according to weeks $\left(\chi_{(4)}^{2}=23.848 ; p<0.01\right)$. Wilcoxon tests showed that significant changes are between weeks 1-3, 1-4, 1-5, 2-4, $2-5,3-5$, and $4-5(p<0.05)$.

According to the result of the Friedman test, the students' levels of attaining the behavior "Being able to play with right hand fingers on the wire" (Beh. 4) of the third composition showed significant development according to weeks $\left(\chi_{(4)}^{2}=22.574 ; p<0.01\right)$. Wilcoxon tests showed that significant changes are between weeks 1-3, 1-4, 1-5, 2-3, 2-4, and 2-5 $(p<0.05)$.

According to the result of the Friedman test, the students' levels of attaining the behavior "Being able to make the appropriate sounds by using different materials such as fishing lines or cassette band on the wire" (Beh. 5) of the third composition showed significant development according to weeks $\left(\chi^{2}{ }_{(4)}=26.210 ; p<0.01\right)$. Wilcoxon tests showed that significant changes are between weeks 1-4, 1-5, 2-5, 3-4, and 4-5 ( $p<0.05)$.

According to the result of the Friedman test, the students' levels of attaining the behavior "Being able to act papidly while playing on the keys and playing extended piano techniques on the wire" (Beh. 6) of the third composition showed significant development according to weeks $\left(\chi_{(4)}^{2}=24.160 ; p<0.01\right)$. Wilcoxon tests showed that significant changes are between weeks 1-3, 1-4, 1-5, 2-3, 2-4, 2-5, 3-4, and 3-5 ( $p<0.05)$.

According to the result of the Friedman test, the students' levels of attaining the behavior "Being able to create the metallic sounds required by the composer" (Beh. 7) of the third composition showed significant development according to weeks $\left(\chi_{(4)}^{2}=22.353 ; p<0.01\right)$. Wilcoxon tests showed that significant changes are between weeks 1-3, 1-4, 1-5, 2-3, 2-4, and 2-5 $(p<0.05)$. 
According to the result of the Friedman test, the students' levels of attaining the behavior "Being able to appropriate and different dynamics of the piece" (Beh. 8) of the third composition showed significant development according to weeks $\left(\chi_{(4)}^{2}=25.000 ; p<0.01\right)$. Wilcoxon tests showed that significant changes are between weeks 1-3, 1-4, 1-5, 2-3, 2-4, 2-5, 3-4, 3-5, and 4-5 $(p<0.05)$.

In consideration of the total mean score, the students' levels of attaining the behaviors of the third composition showed significant development according to weeks $\left(\chi_{(4)}^{2}=33.120 ; p<0.01\right)$. Wilcoxon tests showed that significant changes are between weeks 1-2, 1-3, 1-4, 1-5, 2-3, 2-4, 2-5, 3-4, 3-5, and 4-5 $(p<0.05)$.

The fourth composition. Because the level of the composition was high, 11 of the 16 participating students did not attend the practice and the test was evaluated over five students.

According to the result of the Friedman test, the students' levels of attaining the behavior "Being able to mark the notes with stickers on the piano wire" (Beh. 1) of the fourth composition did not show significant development according to weeks $\left(\chi_{(4)}^{2}=4.000 ; p>0.05\right)$ (see Table 4).

Table 4

Distribution of Target Behavior Scores in the Fourth Composition According to Weeks

\begin{tabular}{|c|c|c|c|c|c|c|c|c|c|c|c|}
\hline \multirow{2}{*}{ Behavior } & \multicolumn{2}{|c|}{ Week 1} & \multicolumn{2}{|c|}{ Week 2} & \multicolumn{2}{|c|}{ Week 3} & \multicolumn{2}{|c|}{ Week 4} & \multicolumn{2}{|c|}{ Week 5} & \multirow{2}{*}{$\begin{array}{l}\chi_{(4)}^{2} \\
(N=5)\end{array}$} \\
\hline & $M$ & $S D$ & $M$ & $S D$ & $\bar{M}$ & $S D$ & $M$ & $S D$ & $M$ & $S D$ & \\
\hline Beh. 1 & 4.80 & 0.447 & 4.87 & 0.447 & 5.00 & 0.000 & 5.00 & 0.000 & 5.00 & 0.000 & 4.000 \\
\hline Beh. 2 & 3.40 & 1.817 & 3.60 & 1.517 & 3.80 & 1.304 & 4.20 & 1.095 & 4.40 & 0.894 & $10.588^{*}$ \\
\hline Beh. 3 & 3.00 & 1.000 & 3.40 & 1.517 & 3.80 & 1.304 & 4.00 & 1.000 & 4.20 & 1.095 & $14.294^{* *}$ \\
\hline Beh. 4 & 2.20 & 0.447 & 2.80 & 0.447 & 3.00 & 0.707 & 3.20 & 0.837 & 4.00 & 1.225 & $13.938^{* *}$ \\
\hline Beh. 5 & 2.80 & 0.447 & 3.40 & 0.894 & 3.40 & 0.894 & 4.00 & 1.414 & 4.20 & 1.095 & $13.563^{* *}$ \\
\hline Beh. 6 & 1.20 & 0.447 & 1.60 & 0.548 & 2.40 & 0.894 & 3.40 & 0.894 & 4.00 & 1.225 & $18.636^{* *}$ \\
\hline Beh. 7 & 3.20 & 1.304 & 3.80 & 1.304 & 4.20 & 1.095 & 4.40 & 0.894 & 4.60 & 0.548 & $13.688^{* *}$ \\
\hline Beh. 8 & 1.60 & 0.548 & 2.20 & 0.447 & 2.80 & 0.837 & 3.20 & 0.837 & 4.00 & 1.000 & $16.964^{* *}$ \\
\hline Beh. 9 & 2.20 & 0.447 & 2.60 & 0.894 & 3.00 & 1.000 & 3.60 & 1.342 & 4.00 & 1.000 & $16.400^{* *}$ \\
\hline Beh. 10 & 2.20 & 0.837 & 2.60 & 0.548 & 3.00 & 1.000 & 3.60 & 0.894 & 4.00 & 1.000 & $14.476^{* *}$ \\
\hline Beh. 11 & 3.00 & 1.225 & 3.40 & 0.894 & 4.00 & 0.707 & 4.20 & 0.837 & 4.60 & 0.548 & $15.792^{* *}$ \\
\hline Beh. 12 & 3.00 & 1.000 & 3.20 & 1.095 & 4.00 & 1.000 & 4.20 & 1.095 & 4.40 & 0.894 & $18.025^{* *}$ \\
\hline Beh. 13 & 3.00 & 1.414 & 3.60 & 1.140 & 4.20 & 1.304 & 4.40 & 0.894 & 4.40 & 0.894 & $14.646^{* *}$ \\
\hline Beh. 14 & 2.80 & 0.837 & 3.20 & 0.837 & 4.20 & 0.837 & 4.20 & 0.837 & 4.40 & 0.894 & $15.200^{* *}$ \\
\hline Beh. 15 & 3.40 & 0.894 & 3.60 & 1.140 & 4.20 & 0.837 & 4.40 & 0.894 & 4.60 & 0.548 & $15.507^{* *}$ \\
\hline Total mean score & 2.79 & 0.363 & 3.19 & 0.409 & 3.67 & 0.429 & 4.00 & 0.497 & 4.32 & 0.502 & $19.755^{* *}$ \\
\hline
\end{tabular}

Note. ${ }^{*} p<0.05$ and ${ }^{* *} p<0.01$ behaviors were scored between $1-5$ points.

According to the result of the Friedman test, the students' levels of attaining the behavior "Being able to read modern notation" (Beh. 2) of the fourth composition showed significant development according to weeks $\left(\chi_{(4)}^{2}=10.588 ; p<0.05\right)$. But none of Wilcoxon tests was significant, so significant changes between weeks could not be determined $(p>0.05)$.

According to the result of the Friedman test, the students' levels of attaining the behavior "Being able to play on prepared piano" (Beh. 3) of the fourth composition showed significant development according to weeks $\left(\chi_{(4)}^{2}=14.294 ; p<0.01\right)$. Wilcoxon tests showed that significant changes are between weeks 1-3, 1-4, and 1-5 $(p<0.05)$.

According to the result of the Friedman test, the students' levels of attaining the behavior "Being able to act rapidly and play in sync while playing on the keys and playing extended piano techniques on the wire" 
(Beh. 4) of the fourth composition showed significant development according to weeks $\left(\chi_{(4)}^{2}=13.938 ; p<\right.$ $0.01)$. Wilcoxon tests showed that significant change is only between weeks 4 and $5(p<0.05)$.

According to the result of the Friedman test, the students' levels of attaining the behavior "Being able to mute the sounds by using left hand on the wire" (Beh. 5) of the fourth composition showed significant development according to weeks $\left(\chi_{(4)}^{2}=13.563 ; p<0.01\right)$. Wilcoxon tests showed that significant changes are between weeks 2-5 and 3-5 $(p<0.05)$.

According to the result of the Friedman test, the students' levels of attaining the behavior "Being able to play the 5th partial harmonic touching the string at proper node" (Beh. 6) of the fourth composition showed significant development according to weeks $\left(\chi_{(4)}^{2}=18.636 ; p<0.01\right)$. Wilcoxon tests showed that significant changes are between weeks 1-4, 1-5, 2-4, 2-5, 3-4, and 3-5 $(p<0.05)$.

According to the result of the Friedman test, the students' levels of attaining the behavior "Being able to use the piano body for percussive usage" (Beh. 7) of the fourth composition showed significant development according to weeks $\left(\chi_{(4)}^{2}=13.688 ; p<0.01\right)$. Wilcoxon tests showed that significant changes is only between weeks 1 and $5(p<0.05)$.

According to the result of the Friedman test, the students' levels of attaining the behavior "Being able to act rapidly while playing on the keys and playing extended piano techniques on the wire" (Beh. 8) of the fourth composition showed significant development according to weeks $\left(\chi_{(4)}^{2}=16.964 ; p<0.01\right)$. Wilcoxon tests showed that significant changes are between weeks 1-5, 2-5, 3-5, and 4-5 $(p<0.05)$.

According to the result of the Friedman test, the students' levels of attaining the behavior "Being able to create metallic sounds required by the composer" (Beh. 9) of the fourth composition showed significant development according to weeks $\left(\chi_{(4)}^{2}=16.400 ; p<0.01\right)$. Wilcoxon tests showed that significant changes are between weeks 1-5, 2-5, and 3-5 $(p<0.05)$.

According to the result of the Friedman test, the students' levels of attaining the behavior "Being able to appropriate and different dynamics of the piece" (Beh. 10) of the fourth composition showed significant development according to weeks $\left(\chi_{(4)}^{2}=14.476 ; p<0.01\right)$. But none of Wilcoxon tests was significant, so significant changes between weeks could not be determined $(p>0.05)$.

According to the result of the Friedman test, the students' levels of attaining the behavior "Being able to play by striking string with heavy metal rodin each hand" (Beh. 11) of the fourth composition showed significant development according to weeks $\left(\chi_{(4)}^{2}=15.792 ; p<0.01\right)$. Wilcoxon tests showed that significant changes are between weeks 1-5, 2-4, and 2-5 $(p<0.05)$.

According to the result of the Friedman test, the students' levels of attaining the behavior "Being able to play with fingernails on the wire" (Beh. 12) of the fourth composition showed significant development according to weeks $\left(\chi_{(4)}^{2}=18.025 ; p<0.01\right)$. Wilcoxon tests showed that significant changes are between weeks 1-3, 1-4, 1-5, 2-3, 2-4, and 2-5 $(p<0.05)$.

According to the result of the Friedman test, the students' levels of attaining the behavior "Being able to strike set of strings on the piano with palm of hand" (Beh. 13) of the fourth composition showed significant development according to weeks $\left(\chi_{(4)}^{2}=14.646 ; p<0.01\right)$. Wilcoxon tests showed that significant changes are between weeks 2-3 and 2-5 $(p<0.05)$.

According to the result of the Friedman test, the students' levels of attaining the behavior "Being able to pluck strings wih guitar pick in each hand" (Beh. 14) of the fourth composition showed significant development according to weeks $\left(\chi_{(4)}^{2}=15.200 ; p<0.01\right)$. But none of Wilcoxon tests was significant, so 
significant changes between weeks could not be determined $(p>0.05)$.

According to the result of the Friedman test, the students' levels of attaining the behavior "Being able to chromatic cluster" (Beh. 15) of the fourth composition showed significant development according to weeks $\left(\chi_{(4)}^{2}=15.507 ; p<0.01\right)$. Wilcoxon tests showed that significant changes are between weeks 1-3, 1-4, 1-5, and 2-4 $(p<0.05)$.

In consideration of the total mean score, the students' levels of attaining the behaviors of the fourth composition showed significant development according to weeks $\left(\chi^{2}{ }_{(4)}=19.755 ; p<0.01\right)$. Wilcoxon tests showed that significant changes are between weeks 1-3, 1-4, 1-5, 2-3, 2-4, 2-5, 3-4, 3-5, and 4-5 ( $p<0.05)$.

The fifth composition. Because the level of the composition was high, three of 16 participating students did not attend the practice and the test was evaluated over 13 students.

According to the result of the Friedman test, the students' levels of attaining the behavior "Being able to mark the notes with stickers on the piano wire" (Beh. 1) of the fifth composition showed significant development according to weeks $\left(\chi_{(4)}^{2}=13.841 ; p<0.01\right)$. Wilcoxon tests showed that significant changes are between weeks 1-4 and 2-4 $(p<0.05)$ (see Table 5).

Table 5

Distribution of Target Behavior Scores in the Fifth Composition According to Weeks

\begin{tabular}{|c|c|c|c|c|c|c|c|c|c|c|c|}
\hline \multirow{2}{*}{ Behavior } & \multicolumn{2}{|c|}{ Week 1} & \multicolumn{2}{|c|}{ Week 2} & \multicolumn{2}{|c|}{ Week 3} & \multicolumn{2}{|c|}{ Week 4} & \multicolumn{2}{|c|}{ Week 5} & \multirow{2}{*}{$\begin{array}{l}\chi_{(4)}^{2} \\
(N=13)\end{array}$} \\
\hline & $M$ & $S D$ & $M$ & $S D$ & $M$ & $S D$ & $M$ & $S D$ & $M$ & $S D$ & \\
\hline Beh. 1 & 4.08 & 0.954 & 4.08 & 0.954 & 4.31 & 0.855 & 4.38 & 0.768 & 4.46 & 0.660 & $13.841^{* *}$ \\
\hline Beh. 2 & 2.62 & 0.870 & 2.85 & 0.689 & 3.15 & 0.899 & 3.46 & 0.877 & 3.69 & 0.947 & $28.979^{* *}$ \\
\hline Beh. 3 & 2.38 & 1.044 & 2.62 & 1.044 & 2.92 & 1.320 & 3.15 & 1.214 & 3.38 & 1.121 & $27.826^{* *}$ \\
\hline Beh. 4 & 2.85 & 0.899 & 3.15 & 0.801 & 3.57 & 1.050 & 3.69 & 1.032 & 3.85 & 1.068 & $30.262^{* *}$ \\
\hline Beh. 5 & 3.08 & 0.760 & 3.23 & 0.725 & 3.62 & 0.870 & 3.85 & 0.889 & 3.92 & 0.862 & $23.815^{* *}$ \\
\hline Beh. 6 & 2.08 & 0.862 & 2.31 & 0.855 & 2.57 & 1.050 & 2.69 & 1.109 & 3.00 & 1.225 & $18.068^{* *}$ \\
\hline Beh. 7 & 3.31 & 1.032 & 3.31 & 1.032 & 3.62 & 1.121 & 3.69 & 1.109 & 4.00 & 1.225 & $21.663^{* *}$ \\
\hline Beh. 8 & 2.62 & 0.650 & 2.77 & 0.599 & 3.31 & 0.947 & 3.85 & 0.801 & 3.92 & 0.862 & $38.045^{* *}$ \\
\hline Beh. 9 & 2.46 & 0.660 & 2.85 & 0.801 & 3.23 & 1.013 & 3.46 & 1.127 & 3.69 & 1.109 & $29.578^{* *}$ \\
\hline Beh. 10 & 1.92 & 0.494 & 2.23 & 0.725 & 2.54 & 0.877 & 2.85 & 0.987 & 3.23 & 1.092 & $29.933^{* *}$ \\
\hline Total mean score & 2.74 & 0.519 & 2.94 & 0.575 & 3.28 & 0.803 & 3.51 & 0.804 & 3.72 & 0.895 & $45.257^{* *}$ \\
\hline
\end{tabular}

Note. ${ }^{*} p<0.05$ and ${ }^{* *} p<0.01$ behaviors were scored between $1-5$ points.

According to the result of the Friedman test, the students' levels of attaining the behavior "Being able to read modern notation" (Beh. 2) of the fifth composition showed significant development according to weeks $\left(\chi_{(4)}^{2}=28.979 ; p<0.01\right)$. Wilcoxon tests showed that significant changes are between weeks 1-3, 1-4, 1-5, 2-3, 2-4, 2-5, 3-4, 3-5, and 4-5 $(p<0.05)$.

According to the result of the Friedman test, the students' levels of attaining the behavior "Being able to play on prepared piano" (Beh. 3) of the fifth composition showed significant development according to weeks $\left(\chi_{(4)}^{2}=27.826 ; p<0.01\right)$. Wilcoxon tests showed that significant changes are between weeks 1-2, 1-4, 1-5, 2-3, $2-4,2-5,3-5$, and $4-5(p<0.05)$.

According to the result of the Friedman test, the students' levels of attaining the behavior "Being able to play glissando with fingernails on the wire" (Beh. 4) of the fifth composition showed significant development according to weeks $\left(\chi_{(4)}^{2}=30.262 ; p<0.01\right)$. Wilcoxon tests showed that significant changes are between weeks 1-2, 1-3, 1-4, 1-5, 2-3, 2-4, 2-5, and 3-5 $(p<0.05)$. 
According to the result of the Friedman test, the students' levels of attaining the behavior "Being able to play glissando with fingertips on the wire" (Beh. 5) of the fifth composition showed significant development according to weeks $\left(\chi_{(4)}^{2}=23.815 ; p<0.01\right)$. Wilcoxon tests showed that significant changes are between weeks 1-2, 1-3, 1-4, 1-5, 2-4, 2-5, and 3-5 ( $p<0.05)$.

According to the result of the Friedman test, the students' levels of attaining the behavior "Being able to play the 2nd partial harmonic touching the string at proper node with left hand" (Beh. 6) of the fifth composition showed significant development according to weeks $\left(\chi_{(4)}^{2}=18.068 ; p<0.01\right)$. Wilcoxon tests showed that significant changes are between weeks 1-3, 1-4, 1-5, and 2-5 $(p<0.05)$.

According to the result of the Friedman test, the students' levels of attaining the behavior "Being able to play pizzicato on the wires" (Beh. 7) of the fifth composition showed significant development according to weeks $\left(\chi_{(4)}^{2}=21.663 ; p<0.01\right)$. Wilcoxon tests showed that significant changes are between weeks 1-3, 1-4, $1-5,2-3,2-4,2-5,3-5$, and $4-5(p<0.05)$.

According to the result of the Friedman test, the students' levels of attaining the behavior "Being able to depress keys silently when using sostenuto pedal" (Beh. 8) of the fifth composition showed significant development according to weeks $\left(\chi_{(4)}^{2}=38.045 ; p<0.01\right)$. Wilcoxon tests showed that significant changes are between weeks 1-3, 1-4, 1-5, 2-3, 2-4, 2-5, 3-4, and 3-5 ( $p<0.05)$.

According to the result of the Friedman test, the students' levels of attaining the behavior "Being able to appropriate and different dynamics of the piece" (Beh. 9) of the fifth composition showed significant development according to weeks $\left(\chi_{(4)}^{2}=29.578 ; p<0.01\right)$. Wilcoxon tests showed that significant changes are between weeks 1-2, 1-3, 1-4, 1-5, 2-3, 2-4, 2-5, and 3-5 ( $p<0.05)$.

According to the result of the Friedman test, the students' levels of attaining the behavior "Being able to act rapidly while playing on the keys and playing extended piano techniques on the wire" (Beh. 10) of the fifth composition showed significant development according to weeks $\left(\chi_{(4)}^{2}=29.933 ; p<0.01\right)$. Wilcoxon tests showed that significant changes are between weeks 1-2, 1-3, 1-4, 1-5, 2-3, 2-4, 2-5, 3-4, and 3-5 ( $p<0.05)$.

In consideration of the total mean score, the students' levels of attaining the behaviors of the fifth composition showed significant development according to weeks $\left(\chi_{(4)}^{2}=45.257 ; p<0.01\right)$. Wilcoxon tests showed that significant changes are between weeks 1-2, 1-3, 1-4, 1-5, 2-3, 2-4, 2-5, 3-4, 3-5, and 4-5 $(p<0.05)$.

The sixth composition. Six of the 16 participating students did not attend the practice and the test was evaluated over 10 students.

According to the result of the Friedman test, the students' levels of attaining the behavior "Being able to mark the notes with stickers on the piano wire" (Beh. 1) of the sixth composition did not show significant development according to weeks $\left(\chi_{(4)}^{2}=4.000 ; p>0.05\right)$ (see Table 6).

According to the result of the Friedman test, the students' levels of attaining the behavior "Being able to read modern notation" (Beh. 2) of the sixth composition showed significant development according to weeks $\left(\chi_{(4)}^{2}=21.053 ; p<0.01\right)$. Wilcoxon tests showed that significant changes are between weeks 1-4, 1-5, 2-5, 3-5, and $4-5(p<0.05)$.

According to the result of the Friedman test, the students' levels of attaining the behavior "Being able to play at prepared piano" (Beh. 3) of the sixth composition showed significant development according to weeks $\left(\chi_{(4)}^{2}=20.500 ; p<0.01\right)$. Wilcoxon tests showed that significant changes are between weeks 1-4, 1-5, 2-4, 2-5, and $3-5(p<0.05)$. 
Table 6

Distribution of Target Behavior Scores in the Sixth Composition According to Weeks

\begin{tabular}{|c|c|c|c|c|c|c|c|c|c|c|c|}
\hline \multirow{2}{*}{ Behavior } & \multicolumn{2}{|c|}{ Week 1} & \multicolumn{2}{|c|}{ Week 2} & \multicolumn{2}{|c|}{ Week 3} & \multicolumn{2}{|c|}{ Week 4} & \multicolumn{2}{|c|}{ Week 5} & \multirow{2}{*}{$\begin{array}{l}\chi_{(4)}^{2} \\
(N=10)\end{array}$} \\
\hline & $M$ & $S D$ & $M$ & $S D$ & $\bar{M}$ & $S D$ & $\bar{M}$ & $S D$ & $M$ & $S D$ & \\
\hline Beh. 1 & 4.50 & 0.527 & 4.50 & 0.527 & 4.60 & 0.516 & 4.60 & 0.516 & 4.60 & 0.516 & 4.000 \\
\hline Beh. 2 & 3.10 & 0.738 & 3.20 & 0.789 & 3.30 & 0.675 & 3.50 & 0.707 & 3.90 & 0.876 & $21.053^{* *}$ \\
\hline Beh. 3 & 2.80 & 1.135 & 2.80 & 1.135 & 3.10 & 0.994 & 3.40 & 1.174 & 3.60 & 1.174 & $20.500^{* *}$ \\
\hline Beh. 4 & 3.10 & 0.876 & 3.30 & 1.059 & 3.60 & 1.075 & 3.80 & 1.229 & 3.80 & 1.229 & $15.781^{* *}$ \\
\hline Beh. 5 & 2.70 & 0.823 & 2.90 & 0.738 & 3.10 & 0.568 & 3.20 & 0.789 & 3.40 & 0.843 & $14.973^{* *}$ \\
\hline Beh. 6 & 2.60 & 0.843 & 2.80 & 0.789 & 3.20 & 1.033 & 3.40 & 1.075 & 3.80 & 1.229 & $25.376^{* *}$ \\
\hline Beh. 7 & 2.20 & 0.919 & 2.40 & 0.843 & 2.60 & 0.843 & 2.80 & 0.919 & 2.90 & 0.994 & $14.087^{* *}$ \\
\hline Total mean score & 3.00 & 0.628 & 3.13 & 0.637 & 3.36 & 0.640 & 3.53 & 0.759 & 3.71 & 0.854 & $36.090^{* *}$ \\
\hline
\end{tabular}

Note. ${ }^{*} p<0.05$ and ${ }^{* *} p<0.01$ behaviors were scored between $1-5$ points.

According to the result of the Friedman test, the students' levels of attaining the behavior "Being able to play glissando with fingertips on the wire" (Beh. 4) of the sixth composition showed significant development according to weeks $\left(\chi_{(4)}^{2}=15.781 ; p<0.01\right)$. Wilcoxon tests showed that significant changes are between weeks 2-4 and 2-5 $(p<0.05)$.

According to the result of the Friedman test, the students' levels of attaining the behavior "Being able to play appropriate and different dynamics of the piece" (Beh. 5) of the sixth composition showed significant development according to weeks $\left(\chi_{(4)}^{2}=14.973 ; p<0.01\right)$. Wilcoxon tests showed that significant changes are between weeks 1-3, 1-4, and 1-5 $(p<0.05)$.

According to the result of the Friedman test, the students' levels of attaining the behavior "Being able to play clusters on the keys" (Beh. 6) of the sixth composition showed significant development according to weeks $\left(\chi_{(4)}^{2}=25.376 ; p<0.01\right)$. Wilcoxon tests showed that significant changes are between weeks 1-3, 1-4, $1-5,2-3,2-4,2-5$, and $4-5(p<0.05)$.

According to the result of the Friedman test, the students' levels of attaining the behavior "Being able to act rapidly while playing on the keys and playing extended piano techniques on the wire" (Beh. 7) of the sixth composition showed significant development according to weeks $\left(\chi_{(4)}^{2}=14.087 ; p<0.01\right)$. Wilcoxon tests showed that significant changes are between weeks 1-3 and 2-4 $(p<0.05)$.

In consideration of the total mean score, the students' levels of attaining the behaviors of the sixth composition showed significant development according to weeks $\left(\chi_{(4)}^{2}=36.090 ; p<0.01\right)$. Wilcoxon tests showed that significant changes are between weeks 1-2, 1-3, 1-4, 1-5, 2-3, 2-4, 2-5, 3-4, 3-5, and 4-5 $(p<0.05)$.

When the levels of attaining the general of the target behaviors of six compositions were examined (see Figure 1), it was observed in the training period of five weeks that:

1. An achievement level of 2.48 points obtained for the first composition in the first week reached a level of 4.39 points in the fifth week and hence a development level of 1.91 points was achieved;

2. An achievement level of 2.93 points obtained for the second composition in the first week reached a level of 4.44 points in the fifth week and hence a development level of 1.51 points was achieved;

3. An achievement level of 2.67 points obtained for the third composition in the first week reached a level of 4.06 points in the fifth week and hence a development level of 1.39 points was achieved; 
4. An achievement level of 2.79 points obtained for the fourth composition in the first week reached a level of 4.32 points in the fifth week and hence a development level of 1.53 points was achieved;

5. An achievement level of 2.74 points obtained for the fifth composition in the first week reached a level of 3.72 points in the fifth week and hence a development level of 0.98 points was achieved;

6. An achievement level of 3.00 points obtained for the sixth composition in the first week reached a level of 3.71 points in the fifth week and hence a development level of 0.71 points was achieved.

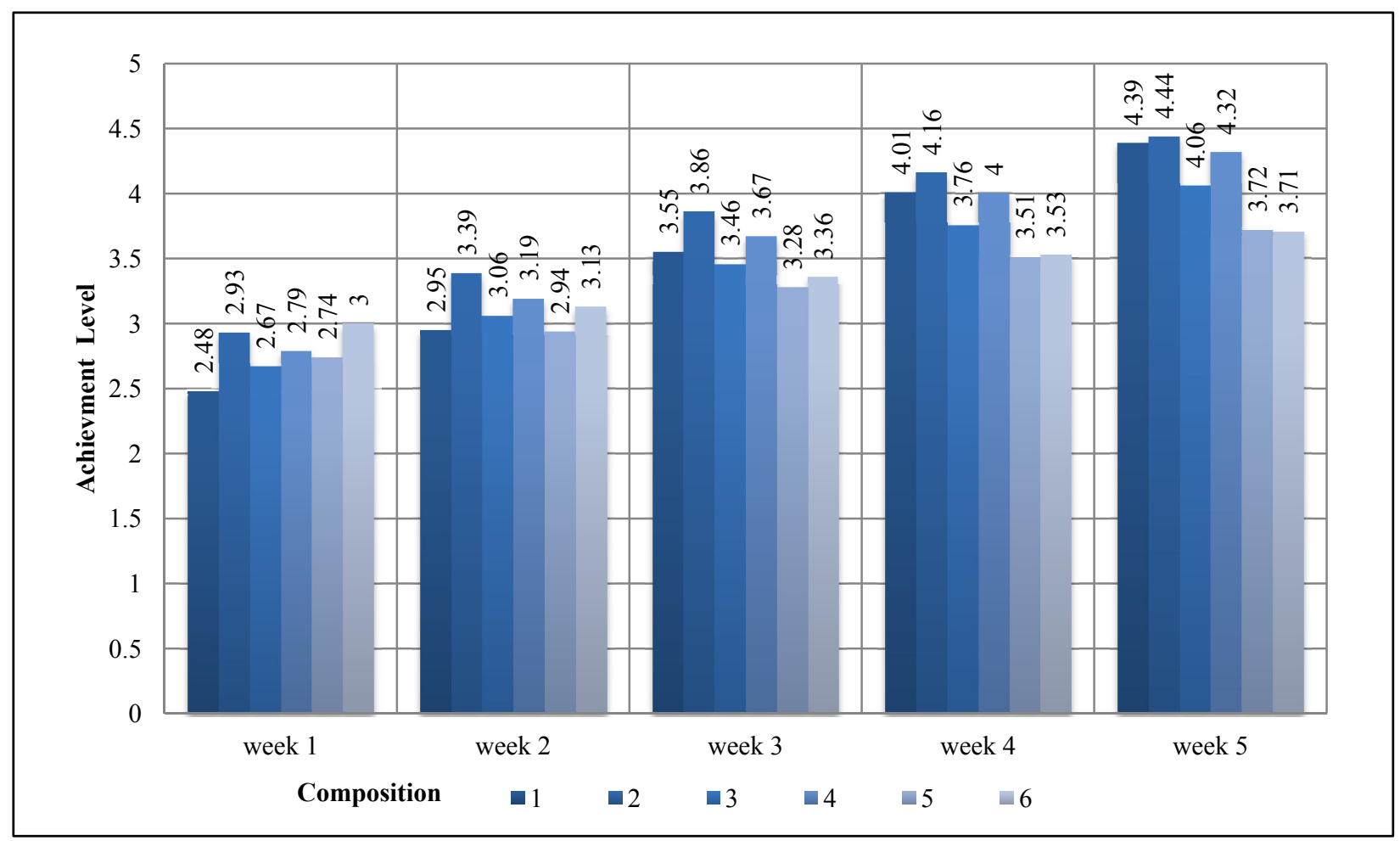

Figure 1. Compositions' target behavior achievement levels according to weeks.

When the measurements made in the first and last weeks are taken into consideration, it can be stated that the first composition greatly developed the target behaviors in the training period of five weeks. It is observed that while the second, third, and fourth compositions developed the target behaviors at a moderate level, the fifth and sixth compositions developed the target behaviors at a lower level compared to the other compositions.

\section{Findings Obtained From the Semi-structured Interview Forms}

As a result of the analysis of the answers given by the participants to the interview questions, themes were identified and then codes and sub-codes were determined by the researchers for these themes. The findings related to the determined codes and sub-codes were examined below.

Opinions of the participants about positive aspects of the project. All of the students participating in the interview stated that the project made them acquire a different perspective: $(\mathrm{P} 1)^{2}$

Apart from getting to know the piano theoretically, I also practiced different ways of obtaining sound with the piano.

\footnotetext{
${ }^{2}$ P: Participant.
} 
I realized that I acquired a new point of view related to playing the piano with the techniques which we learned every passing day. For me, playing the piano became more than using the keys. (P2)

Modern piano techniques made me think that I could play it in different ways, about different musical note analyses and how composers play the piano with different techniques. (P3)

With this project, I think our department, music education, has made the students acquire different viewpoints. (P4)

Thanks to this project, I arrived at the awareness of the presence of countless ways of playing an instrument. (P5)

In that period, I regarded this activity which we performed as a step taken to expand our viewpoint. (P6)

Moreover, five participants found this project positive in terms of developing their knowledge:

As an experienced person, I am knowledgeable, though little, about playing and technique. (P1)

I learned to play the piano not only by pressing its keys, but also touching its strings. (P3)

In the direction of what the participating students told and the briefing made in the project presentation, it made us gain clear knowledge directly or indirectly about today's modern music and its effects on people. (P4)

I think this project improved me. (P5)

I regarded this project as a step taken to expand our viewpoint. (P6)

Opinions of the participants about negative aspects of the project. One of the students participating in the interview stated that the time was limited. However, one participant stated a negative opinion by finding the study too detailed:

In my opinion, the only negative aspect of this training was that it lasted very short. (P2)

I think this project is too detailed for music education departments. (P4)

Opinions of the participants about the contribution of the project. The participating students stated that they gained basic knowledge about extended piano techniques thanks to the applied project and it was privilege for them. Moreover, they expressed that this project changed their viewpoints about the piano and it was beneficial in terms of following novelties in art:

I can guide and enlighten my students about extended piano techniques. Moreover, it was a process which was necessary for my academic career and would provide a privilege when compared to many piano players. (P1)

For me, playing the piano was no longer using the keys and became more than this. Participating in this project made the relationship between me and the piano, which had become monotonous, more entertaining, and beautiful. (P2)

Participating in this project will enable me to perform such kinds of compositions knowingly both now and in the future. I think there is always a way of advancing in art and this project was beneficial for me. (P3)

That we learned and practiced different musical note analyses within the scope of this project will facilitate our performing these kinds of compositions in the future. (P4)

Thanks to this project, I arrived at the awareness of the presence of countless ways of using an instrument. I also understood that a nice composition could be created in a completely limitless way and by pulling all patterns down. (P5)

I think this project was useful for us, as a piano teacher, to get to know current changes in order to be able to answer the needs of children and young people who cover/will cover distances faster than us. (P6)

\section{Conclusion}

When the statistical data obtained with the measurements made with the personal observation forms in the first and last weeks are taken into consideration, it can be stated that in the training period of five weeks, the first composition developed the target behaviors greatly. It is observed that while the second, third, and fourth compositions developed the target behaviors at a moderate level, the fifth and sixth compositions developed the target behaviors at a lower level when compared to the other compositions.

According to the answers given by six students to the semi-structured interview questions, all the students 
found the project useful in terms of having them acquire a different viewpoint and five students in terms of developing their knowledge. One student expressed that the time was insufficient; one student expressed negative opinion by finding the study too detailed. The authenticity of the study comes from the fact that these piano techniques were new for students taking education at education faculties and practiced for the first time.

The assumption that these students trained with the modern piano techniques at the practicing stage of the project would adapt to these techniques, be able to perform compositions written with these techniques and appropriate for their levels and in this way develop appropriate viewpoints toward different playing techniques of the art of music in the following years and these different playing techniques would reinforce students' sense of self-confidence and increase their learning motivation levels (İsmail \& Şirin, 2013).

It is expected that the practice will also set an example for other institutions training music educators, cause modern techniques to be given more place in piano education, and make a contribution to the training of future music educators more equipped and with a more modern viewpoint about contemporary music.

\section{References}

Adam, B. (2010). Extended techniques for piano. Retrieved from http://www.lunanova.org/PianoET/

Adam, B. (2015). Extended techniques for piano: Clusters. Retrieved from http://www.lunanova.org/PianoET/CLcr.html

Adam, B. (2015). Extended techniques for piano: Glissando Ex. 3. Retrieved from http://www.lunanova.org/PianoET/GL3.html

Can, S. B. (2002). John Cage' in "hazırlanılmıs piyano" suve Endonezya geleneksel orkestrası "gamelan" (John Cage's "prepared piano" and Indonesian traditional orchestra "gamelan") (D.M.A. dissertation, Social Science Institution, Eskişehir).

İsmail, B., \& Şirin, A. D. (2013). Extended piano techniques and teaching in music education departments (Project Final Concert Program Notes, Bursa).

Nilüfer, Y. (2012). Müzik öğretmenliği eğitiminde modern piyano tekniklerinin öğretimive uludağ üniversitesi örneği kapsamında proje uygulamasının ön değerlendirilmesi (Teaching extended techniques in Music Education Department and preliminary evaluation of scope of project implementation example UU). Paper presented at The New Trends on Global Education Conference, Kyrenia, Cyprus.

Piano extended technique. (2010). In Wikipedia, the free encyclopedia. Retrieved from http://en.wikipedia.org/wiki/Piano_extend ed_technique

Prepared piano. (2010). In Wikipedia, the free encyclopedia. Retrieved from http://en.wikipedia.org/wiki/Prepared_piano

Şirin, A. (2010). The use of extended piano techniques at conservatories in Turkey. Procedia-Social and Behavioral Sciences, 2(2), 3080-3087. Retrieved from http://www.sciencedirect.com/science/article/pii/S1877042810005094

Şirin, A. D. (2012, May 16-18). Extended piano techniques and two examples. In the abstract book of The International Conference: Innovative Research in a Changing and Challenging World, Phuket, Thailand.

Şirin, A. D. (2013). Extended piano techniques and two examples. In the abstract book of The 3rd International Conference on Performing Arts as Creative Industries in Asia, Malezya.

Şirin, A. D., \& Mesruh, S. (2012). Modern piyano teknikleri ve iki eser (Extended piano techniques and two examples). International Journal of New Trends in Arts, Sports and Science Education, 1(3), 59-67.

String piano. (2010). In Wikipedia, the free encyclopedia. Retrieved from http://en.wikipedia.org/wiki/String_piano 